\title{
Pregnancy-Associated Plasma Protein A (PAPP-A) as a potential biomarker for risk stratification assistance of nonviable pregnancy
}

\author{
Edwin W Holt and William E Roudebush* \\ Department of Biomedical Sciences, University of South Carolina School of Medicine Greenville, 701 Grove Road, Greenville, South Carolina
}

\begin{abstract}
Background: This retrospective cohort study compared pregnancy-associated plasma protein A (PAPP-A) levels in sera obtained from women with viable intrauterine pregnancies to those with nonviable pregnancies following assisted reproductive technology.

Methods: Women with positive $\beta \mathrm{hCG}$ measurements were categorized into two groups: (a) nonviable pregnancy, including biochemical pregnancy ( $\beta \mathrm{hCG}$ 5-50 $\mathrm{mIU} / \mathrm{mL}$ ) and pregnancies with $\beta \mathrm{hCG}>50 \mathrm{mIU} / \mathrm{mL}$ which did not double within 72 hours, and (b) viable pregnancy ( $\beta \mathrm{hCG}>50 \mathrm{mIU} / \mathrm{mL}$ which at least doubled within 72 hours). PAPP-A levels between 4 weeks-4 days and 6 weeks-3 days were compared for viable and nonviable pregnancies.

Results: Twenty-five pregnant women undergoing IVF-ET were followed for this study, 7 resulted with a biochemical pregnancy, 5 with an ectopic pregnancy, and 13 with a viable intrauterine pregnancy. Serum samples from each patient $(\mathrm{n}=97$ samples $)$ were assayed for PAPP-A. PAPP-A levels ranged from $0.60 \mathrm{ng} / \mathrm{mL}$ to 3.3 $\mathrm{ng} / \mathrm{mL}$ with analytical and functional sensitivities of $0.2 \mathrm{ng} / \mathrm{mL}$ and $<2.5 \mathrm{ng} / \mathrm{mL}$, respectively. Mean PAPP-A levels for each group were: biochemical, $1.56 \mathrm{ng} / \mathrm{mL}$; nonviable, $0.90 \mathrm{ng} / \mathrm{mL}$; and viable, $1.63 \mathrm{ng} / \mathrm{mL}$. A receiver operator curve demonstrated a definitive PAPP-A cut-off value for a viable pregnancy of $>1.25 \mathrm{ng} / \mathrm{mL}$ with a sensitivity of 69.2 and a specificity of 100.0 at a gestational age of 5 weeks- 4 days.
\end{abstract}

Conclusions: From gestational week 5 onwards in normal pregnancies, PAPP-A was significantly increased in normal viable pregnancies over nonviable pregnancies In nonviable pregnancy, PAPP-A appeared to remain low for the entire observation period. PAPP-A appears to be a suitable biomarker for (non)viable pregnancies.

\section{Introduction}

Pregnancy-associated plasma protein A (PAPP-A) is a placentaderived glycoprotein produced by trophoblastic cells, which rises gradually during the early weeks of a viable pregnancy. Its biological function is unknown but measuring serum levels has proven useful in a number of abnormal obstetrical conditions [1]. Currently, serum quantitative $\beta$-hCG levels and ultrasound are utilized for following early pregnancies and, ultimately, separating viable from nonviable pregnancies (miscarriages and ectopic pregnancies); however, diagnosis is often delayed due to limitations of these tests.

When a female patient presents to the Emergency Department (ED) with abdominal pain with or without vaginal bleeding, her pregnancy status must always be determined. If she is of postmenopausal age, pregnancy can generally be ruled out. This is equally true for pre-pubescent children. However, for females of childbearing age, the possibility of fertility and parturition ought to be a diagnostic consideration in order to rule out ectopic pregnancy [2]. Screening for pregnancy starts with the collection of a sexual history and may include serum quantitative $\beta$-hCG levels and ultrasound. These tests, however, are not always conclusive and can result in a patient being sent home undiagnosed with a potentially life-threatening ectopic pregnancy [3].

An ectopic pregnancy occurs with implantation of the embryo outside of the uterus. In $95 \%$ of ectopic pregnancies, implantation occurs in the oviduct and is called a tubal pregnancy. Implantation can also occur in the ovaries, cervix, or abdomen [4]. If left untreated, the developing fetus will continue to grow, leading to life-threatening consequences for the mother. Although ectopic pregnancy only accounts for $2 \%$ of pregnancies in the United States, it is the leading cause of pregnancy-related mortality and morbidity in the first trimester [5]. The most common complication associated with ectopic pregnancy is tubal rupture with internal bleeding, which can lead to shock [6]. Tubal ectopic pregnancy has also been associated with consequent infertility later on due to compromise of the tubal architecture [7]. While death from rupture is rare in women who have access to modern medical facilities, ectopic pregnancy accounts for 6-9\% of all pregnancy-related deaths [8,9]. Risk factors for ectopic pregnancy include previous ectopic pregnancy, prior tubal surgery, documented tubal pathology, in utero diethylstilbestrol (DES) exposure, previous genital infections (eg. chlamydia, gonorrhea), Pelvic Inflammatory Disease (PID), infertility, smoking, more than one lifetime sexual partners, and current intrauterine device use [10].

${ }^{\star}$ Correspondence to: William E Roudebush, $\mathrm{PhD}$, Department of Biomedical Sciences, University of South Carolina School of Medicine Greenville, Greenville, South Carolina 29605, USA, E-mail: 864-455-9842; Fax 864-455-8404; E-mail: roudebus@greenvillemed.sc.edu

Key words: pregnancy-associated plasma protein $A, P A P P-A$, ectopic, ectopic pregnancy

Received: January 04, 2019; Accepted: January 18, 2019; Published: January 21, 2019 
In assisted reproductive technology (ART) pregnancies, ectopic pregnancy rate occurs $2-2.5 \%$ of the time, increasing with multiple embryo transfer [11]. The prevalence of ectopic pregnancy increases to $7-13 \%$ in ED populations [12,13]. As women are now able to become pregnant at more advanced ages, maternal age remains a dangerous risk factor for ectopic pregnancy [4]. Prompt recognition and diagnosis of ectopic pregnancy is critical to improving outcomes. Symptoms of ectopic pregnancy include acute abdominal pain and vaginal bleeding, and they typically occur six to eight weeks after the patient's last normal menstrual period [2]. A patient may not even be aware that she is pregnant, which compounds the difficulty in diagnosing her. When symptoms like pelvic pain are seen in the ED, they may be mistaken for less serious conditions, despite the proper laboratory and image diagnostic tests being conducted. According to the general schematic for ectopic pregnancy evaluation that has been practiced in EDs for decades, $50 \%$ of cases of ectopic pregnancy were missed at initial presentation [14]. The American College of Emergency Physicians and The American College of Obstetrics and Gynecology currently recommends the following decision tree flow chart for diagnosing a suspected ectopic pregnancy (Figure 1).

If a woman with abdominal pain or vaginal bleeding cannot be stabilized, she is immediately sent to surgery for a consult. If she is stable, she is evaluated for ectopic pregnancy. If her risk is low, a serum $\beta$-hCG level, which becomes elevated early in pregnancy and is measured by home pregnancy tests, will be drawn. If that level is above $1,500 \mathrm{mIU} /$
$\mathrm{mL}$, she will be sent for abdominal ultrasound. If her level is below 1,500 $\mathrm{mIU} / \mathrm{mL}$, it cannot be concluded that she is not pregnant. She requires further testing, however this must be done 48 hours later, and so she is sent home and told to follow up with her primary care provider (PCP) for monitoring. Similarly, if ultrasound of a medium-high risk patient is indeterminate of ectopic pregnancy, a $\beta$-hCG level will be tested, and she will be sent home if this level is not above $1,500 \mathrm{mIU} / \mathrm{mL}$. This is the current system that ED physicians use for treating ectopic pregnancy, and it leaves a dangerous amount of room for missed diagnoses. The purpose of this study was to investigate a biomarker already used for screening Trisomy 21 and other aneuploidies with regards to its function as an aid in stratifying risk of nonviable pregnancy.

\section{Materials and methods}

The study was a retrospective cohort review of the PAPP-A levels of twenty-seven women undergoing in vitro fertilization and embryo transfer (IVF-ET) at a tertiary fertility clinic. PAPP-A levels in human sera obtained from women with viable intrauterine pregnancies were compared to those with nonviable pregnancies following assisted reproductive technology. Women with positive $\beta$ hCG measurements 14 days after IVF transfer were categorized into two groups: (a) nonviable pregnancy, including biochemical pregnancy ( $\beta$ hCG 5-50 $\mathrm{mIU} / \mathrm{mL}$ ) and pregnancies with $\beta \mathrm{hCG}>50 \mathrm{mIU} / \mathrm{mL}$ which did not double within 72 hours, and (b) viable pregnancy $(\beta \mathrm{hCG}>50 \mathrm{mIU} / \mathrm{mL}$ which at least doubled within 72 hours). Serum cardiac PAPP-A levels

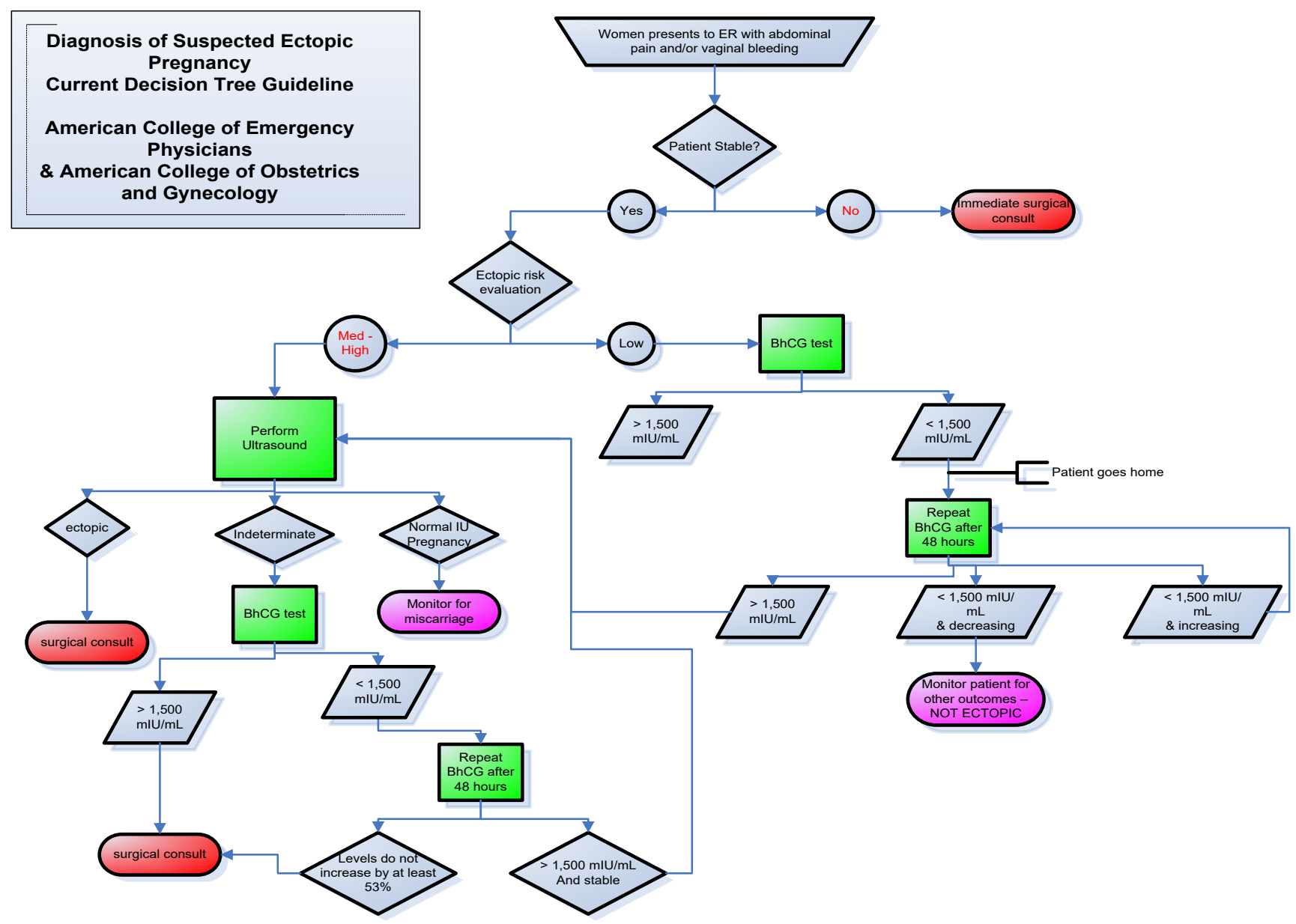

Figure 1. Diagnosis of suspected ectopic pregnancy current decision tree guideline 
were measured via an ultrasensitive enzyme-linked immunosorbent ELISA assay (Beckman Coulter, Chaska, MN). PAPP-A levels between 4 weeks- 4 days and 6 weeks-3 days were compared for viable and nonviable pregnancies. This measurement period spanned the critical time when an ED physician would need to verify a pregnant patient. Samples from twenty-five pregnant women were assayed for PAPP-A. Of these women, 7 were biochemical pregnancies, 5 were ectopic pregnancies, and 13 were viable intrauterine pregnancies.

\section{Results}

Twenty-five pregnant women undergoing IVF-ET were followed for this study, 7 resulted with a biochemical pregnancy, 5 with an ectopic pregnancy, and 13 with a viable intrauterine pregnancy. Three or four serum samples from each patient $(\mathrm{n}=97$ samples) were assayed for PAPP-A as described.

As shown in Table 1, the levels of PAPP-A ranged from $0.60 \mathrm{ng} /$ $\mathrm{mL}$ to $3.30 \mathrm{ng} / \mathrm{mL}$ with analytical and functional sensitivities of 0.2 $\mathrm{ng} / \mathrm{mL}$ and $<2.5 \mathrm{ng} / \mathrm{mL}$, respectively. The minimum PAPP-A levels for each group were: viable, $0.60 \mathrm{ng} / \mathrm{mL}$; nonviable: biochemical, $0.90 \mathrm{ng} /$ $\mathrm{mL}$; and ectopic, $0.65 \mathrm{ng} / \mathrm{mL}$, while the maximum PAPP-A levels for each group were: viable, 3.30; nonviable: biochemical, $2.35 \mathrm{ng} / \mathrm{mL}$; and ectopic, $1.25 \mathrm{ng} / \mathrm{mL}$. Mean PAPP-A levels for each group were: viable, $1.63 \mathrm{ng} / \mathrm{mL}$; nonviable: biochemical, $1.56 \mathrm{ng} / \mathrm{mL}$; and ectopic, $0.90 \mathrm{ng} /$ $\mathrm{mL}$. Median PAPP-A levels for each group were: viable, $1.60 \mathrm{ng} / \mathrm{mL}$; nonviable: biochemical, $1.45 \mathrm{ng} / \mathrm{mL}$; and ectopic, $0.85 \mathrm{ng} / \mathrm{mL}$. The standard deviation values for the viable, nonviable: biochemical, and ectopic pregnancy groups were $0.221,0.195$, and 0.100 , respectively.

A receiver operating curve of data collected demonstrated a definitive PAPP-A cut-off value (criterion) for a viable pregnancy of $>1.25 \mathrm{ng} / \mathrm{mL}$ with a sensitivity of 69.2 and a specificity of 100.0 (Figure 2) at gestational age 5 weeks-4 days (5.4) (Figure 3). At 5 weeks- 4 days, PAPP-A levels for viable pregnancy increase exponentially, while PAPP-A levels for nonviable pregnancy do not. Levels of PAPP-A for viable pregnancy were measured and plotted up to 6 weeks-3 days (6.3) (Figure 3).

It was found that at approximately gestational age 5 weeks- 4 days and onwards, PAPP-A was significantly increased in normal viable pregnancies over nonviable pregnancies. In nonviable pregnancy, PAPP-A appeared to remain low for the entire observation period (Figure 3).

\section{Discussion and conclusion}

In general, $95 \%$ of women who present to the ED with pelvic pain, with or without vaginal bleeding, leave without a diagnosis or any further information about what is going on within their bodies to cause their pain [15]. Even worse, $40-50 \%$ of ectopic pregnancies are misdiagnosed at the initial ED visit [3]. Current ED protocol says that when a stable female patient of childbearing age enters the ED with

Table 1. Pregnancy type breakdown of patient population and assay characteristics

\begin{tabular}{|c|c|c|c|}
\hline & Biochemical & Ectopic & Viable \\
\hline Number & 7 & 5 & 13 \\
\hline Mean (ng/mL) & 1.56 & 0.90 & 1.63 \\
\hline Median (ng/mL) & 1.45 & 0.85 & 1.60 \\
\hline Standard Deviation (Std Dev) & 0.195 & 0.100 & 0.221 \\
\hline Minimum (ng/mL) & 0.90 & 0.65 & 0.60 \\
\hline Maximum (ng/mL) & 2.35 & 1.25 & 3.30 \\
\hline Assay Sensitivity & $\begin{array}{c}\text { Analytical } \\
\text { Functional }\end{array}$ & $\begin{array}{c}<.2 \mathrm{ng} / \mathrm{mL} \\
<2.5 \mathrm{ng} / \mathrm{mL}\end{array}$ \\
\hline
\end{tabular}

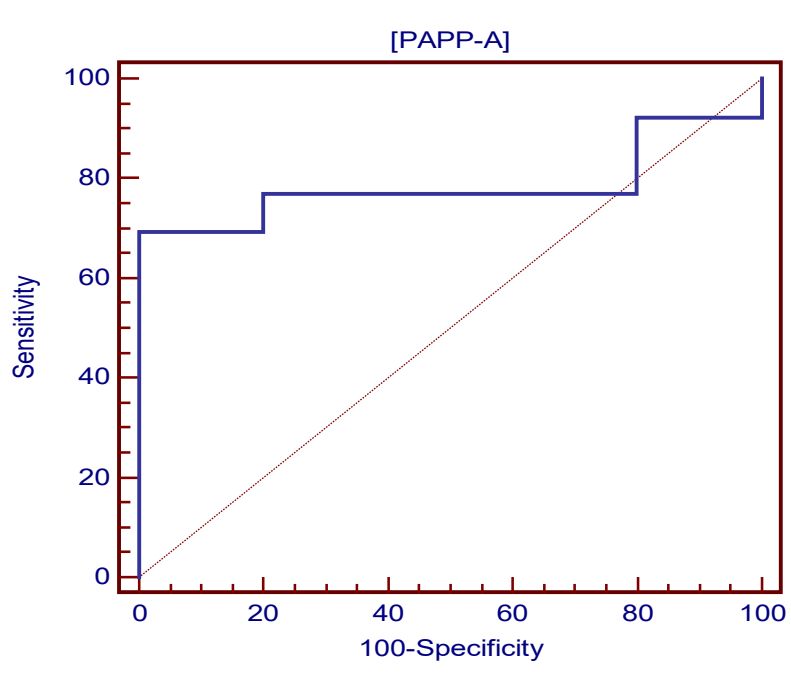

Figure 2. Receiver operator curve for PAPP-A and viable pregnancy outcome

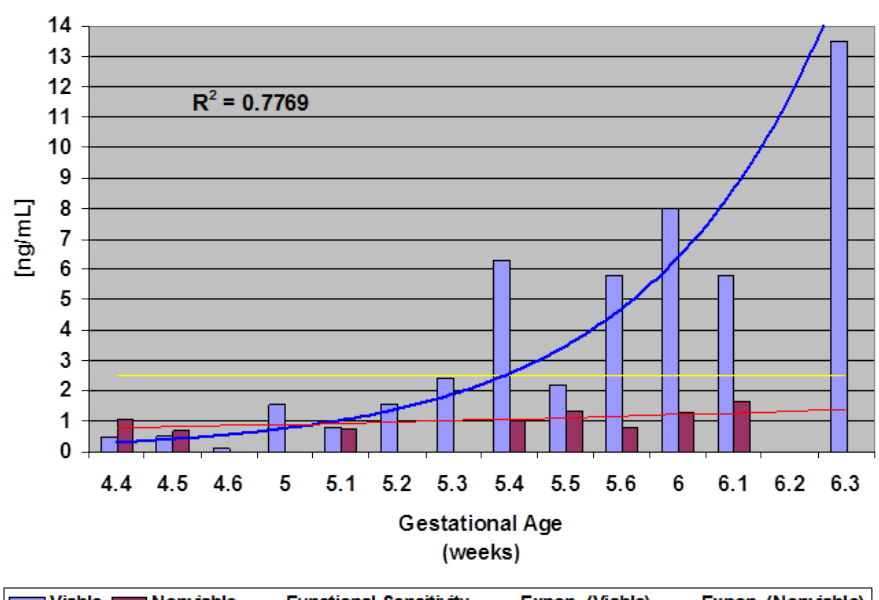

$\square$ Viable $\square$ Nonviable Functional Sensitivity —Expon. (Viable) —Expon (Nonviable)

Figure 3. PAPP-A and pregnancy outcomes (Viable vs. Nonviable) by gestational week

abdominal pain, pregnancy must be considered in the differential diagnoses. If her exam is otherwise normal and her $\beta$ hCG levels are below a specific threshold $(<1,500 \mathrm{mIU} / \mathrm{mL})$, she will be sent home and referred to her primary care physician. The reality is that a follow-up in 48 hours to recheck $\beta$ hCG levels may not be an option for every woman that is sent home from the ED. There are a myriad of factors that could deter a patient from being tested again in the recommended 48 hours. These include, but are not limited to, inability to pay or find adequate transportation, lack of time, and lack of enthusiasm to further subject themselves to waiting rooms, blood draws, and invasive medical evaluation. Furthermore, when $\beta$ hCG is above the necessary threshold to indicate pregnancy, the next step is ultrasound evaluation, and that presents another logistical challenge. Ultrasound technology is not always available in the clinical setting, and the personnel skilled to operate and read ultrasound are not ubiquitous. If there were another biomarker that could supplement hCG and more precisely identify ectopic pregnancy, this patient population would greatly benefit from it.

A diagnostic test is needed for patients that typically present during early pregnancy (e.g. $\sim 6$ weeks) that would rule out an ectopic pregnancy [15]. It was the goal of this study to investigate PAPP-A as an aid for nonviable pregnancy risk stratification. Compared to previous research in which the PAPP-A assays were not specific 
enough, this study revealed that serum PAPP-A is significantly higher in viable pregnancies than in nonviable pregnancies after about 5 weeks gestation. Furthermore, PAPP-A appears to remain low in nonviable pregnancies throughout these initial 5 weeks.

This research indicates that serum PAPP-A, in conjunction with $\beta$ hCG, could be evaluated for early diagnosis of ectopic pregnancy. Early diagnosis could lead to early management and decreased risk of mother morbidity and mortality, most dramatically in the developing where lack of resources means that intervention often comes too late and case fatality rates are as high as $27 \%[16,17]$. In addition to lives saved, early diagnosis of ectopic pregnancy could mean improved rates of infertility associated with tubal rupture and architectural compromise. These improved patient outcomes may be particularly dramatic among populations of women that face more barriers in terms of access to healthcare.

In conclusion, from gestational week 5 onwards in normal pregnancies, PAPP-A was significantly increased in normal viable pregnancies over nonviable pregnancies. In nonviable pregnancy, PAPP-A appeared to remain low for the entire observation period. Pregnancy-associated plasma protein A (PAPP-A) appears to be a suitable biomarker for risk stratification of nonviable pregnancies.

\section{Acknowledgements}

The authors greatly appreciate the clinical insights of Benjie Mills, MD, Department of Obstetrics \& Gynecology, Greenville Health System, Greenville, SC.

\section{References}

1. Conover CA (2012) Key questions and answers about pregnancy-associated plasma protein-a. Trends Endocrinol Metab 23: 242-249. [Crossref]

2. Chung K, Allen R (2008) The use of serial human chorionic gonadotropin levels to establish a viable or a nonviable pregnancy. Semin Reprod Med 26: 383-390. [Crossref]

3. Kaplan BC, Dart RG, Moskos M, Kuligowska E, Chun B, et al. (1996) Ectopic pregnancy: Prospective study with improved diagnostic accuracy. Ann Emerg Med 28: 10-17. [Crossref]
4. Rana P, Kazmi I, Singh R, Afzal M, Al-Abbasi FA, et al. (2013) Ectopic pregnancy: A review. Arch Gynecol Obstet 288: 747-757. [Crossref]

5. Mol BW, Matthijsse HC, Tinga DJ, Huynh T, Hajenius PJ, et al. (1998) Fertility after conservative and radical surgery for tubal pregnancy. Hum Reprod 13:1804-1809. [Crossref]

6. Mikhail E, Salemi JL, Schickler R, Salihu HM, Plosker S, et al. (2018) National rates, trends and determinants of inpatient surgical management of tubal ectopic pregnancy in the United States, 1998-2011. J Obstet Gynaecol Res 44: 730-738. [Crossref]

7. Agdi M, Tulandi T (2009) Surgical treatment of ectopic pregnancy. Best Pract Res Clin Obstet Gynaecol 23: 519-527. [Crossref]

8. Centers for Disease Control and Prevention (1995) Ectopic pregnancy - United States, 1990-1992. MMWR Morb Mortal Wkly Rep 44: 46-48. [Crossref]

9. Chang J, Elam-Evans LD, Berg CJ, Herndon J, Flowers L, et al. (2003) Pregnancyrelated mortality surveillance - United States, 1991-1999. MMWR Surveill Summ 52: 1-8. [Crossref]

10. Dart RG, Kaplan B, Varaklis K (1999) Predictive value of history and physical examination in patients with suspected ectopic pregnancy. Ann Emerg Med 33: 283290 .

11. Perkins KM, Boulet SL, Kissin DM, Jamieson DJ, National ARTSG (2015) Risk of ectopic pregnancy associated with assisted reproductive technology in the United States, 2001-2011. Obstet Gynecol 125: 70-78. [Crossref]

12. Kohn MA, Kerr K, Malkevich D, O'Neil N, Kerr MJ, et al. (2003) Beta-human chorionic gonadotropin levels and the likelihood of ectopic pregnancy in emergency department patients with abdominal pain or vaginal bleeding. Acad Emerg Med 10: 119-126. [Crossref]

13. Barnhart K, Mennuti MT, Benjamin I, Jacobson S, Goodman D (1994) Prompt diagnosis of ectopic pregnancy in an emergency department setting. Obstet Gynecol 84: 1010-1015. [Crossref]

14. Stovall TG, Kellerman AL, Ling FW, Buster JE (1990) Emergency department diagnosis of ectopic pregnancy. Ann Emerg Med 19: 1098-1103. [Crossref]

15. Matteson KA, Weitzen SH, Lafontaine D, Phipps MG (2008) Accessing care: use of a specialized women's emergency care facility for nonemergent problems. $J$ Women Health (Larchmt) 17: 269-277. [Crossref]

16. Baffoe S, Nkyekyer K (1999) Ectopic pregnancy in Korle Bu Teaching Hospital, Ghana: a three-year review. Trop Doct 29: 18-22. [Crossref]

17. Goyaux N, Leke R, Keita N, Thonneau P (2003) Ectopic pregnancy in African developing countries. Acta Obstet Gynecol Scand 82: 305-312. [Crossref]

Copyright: (C2019 Holt EW. This is an open-access article distributed under the terms of the Creative Commons Attribution License, which permits unrestricted use, distribution, and reproduction in any medium, provided the original author and source are credited. 